\title{
Heliostat Reflective Surface Substrate Characterization
}

N. R. Gordon

November 1978

Prepared for the U.S. Department of Energy under Contract EY-76-C-06-1830

Pacific Northwest Laboratory Operated for the U.S. Department of Energy by Battelle Memorial Institute 


\title{
NOTICE
}

This report was prepared as an account of work sponsored by the United States Government. Neither the United States nor the Department of Energy, nor any of their employees, nor any of their contractors, subcontractors, or their employees, makes any warranty, express or implied, or assumes any legal liability or responsibility for the accuracy, completeness or usefulness of any information, apparatus, product or process disclosed, or represents that its use would not infringe privately owned rights.

The views, opinions and conclusions contained in this report are those of the contractor and do not necessarily represent those of the United States Government or the United States Department of Energy.

\author{
PACIFIC NORTHWEST LABORATORY \\ operated by \\ BATTELLE \\ for the \\ UNITED STATES DEPARTMENT OF ENERGY \\ Under Contract EY-76-C-06-1830
}

\begin{tabular}{|c|c|c|}
\hline \multicolumn{3}{|c|}{$\begin{array}{c}\text { Printed in the United States of An } \\
\text { Available from } \\
\text { National Technical Information S } \\
\text { United States Department of Com } \\
5285 \text { Port Royal Road } \\
\text { Springfield, Virginia } 22151\end{array}$} \\
\hline Price: & Printed Copy & _: Microfi \\
\hline & •Pages & $\begin{array}{c}\text { NTIS } \\
\text { Selling Price }\end{array}$ \\
\hline & $001-025$ & $\$ 4.00$ \\
\hline & $026-050$ & $\$ 4.50$ \\
\hline & $051-075$ & $\$ 5.25$ \\
\hline & $076-100$ & $\$ 6.00$ \\
\hline & $101-125$ & $\$ 6.50$ \\
\hline & $126-150$ & 57.25 \\
\hline & $151-175$ & $\$ 8.00$ \\
\hline & $176-200$ & $\$ 9.00$ \\
\hline & $201-225$ & $\$ 9.25$ \\
\hline & $226-250$ & $\$ 9.50$ \\
\hline & $251-275$ & 510.75 \\
\hline & $276-300$ & $\$ 11.00$ \\
\hline
\end{tabular}


PNL-2810

$U C-62$

\section{4}

HELIOSTAT REFLECTIVE SURFACE SUBSTRATE

CHARACTERI ZATION

N. R. Gordon

November 1978

Prepared for

the U.S. Department of Energy

under Contract EY-76-C-06-1830

Pacific Northwest Laboratory

Richland, Washington 99352 
This report is the result of surveys and technical analyses performed for Sandia Laboratories in support of the U.S. Department of Energy, Solar Thermal Large Power System. The purpose of the surveys and analyses are to provide background information and procurement specifications for materials which have potential application in heliostat construction. This report covers the work performed under the reflective surface substrates characterization and specification task. The report emphasizes the properties of foam core sandwich constructions. 


\section{TABLE OF CONTENTS}

FORWARD. ......................... LIST OF FIGURES. ..................... $i$. . . . .

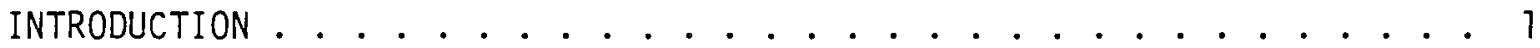
THEORETICAL ANALYSIS . . . . . . . . . . . . . 2 VISCOELASTIC ANALYSIS. . . . . . . . . . . . . . 3

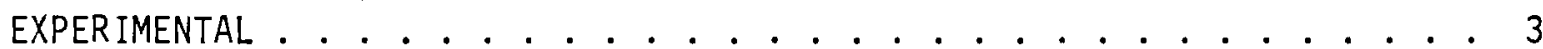

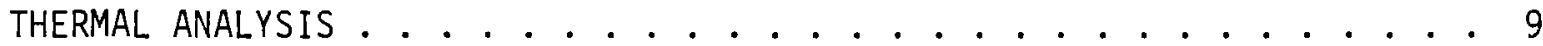
CONCLUSIONS AND RECOMMENDATIONS. . . . . . . . . . . 10 APPENDIX A . . . . . . . . . . . . . . . . A-1

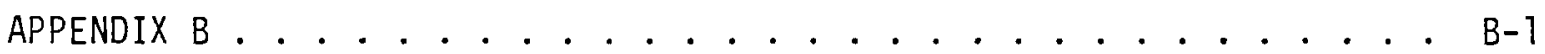
REFERENCES 


\section{LIST OF FIGURES}

1. Experimental Test Specimen. . . . . . . . . . . . . . . 4

2. Stress Relaxation of Experimental Test Specimens. . . . . . . . . 6

3. 24-Hour Stress Relaxation of an Experimental Test Specimen. . . . 7

4. Time-Temperature Superposition of Stress Relaxation Test Data. . 8

A-1. Sandwich Structure Used for Theoretical Analysis. . . . . . . . A-2

B-2. Stress Relaxation Curves Used for Time-Temperature Superposition. . B-2

B-3. Determination of the WLF Constants. . . . . . . . . . . . . B-3 


\section{INTRODUCTION}

A mirror module design for use on heliostats for power generation requires that distortion of the mirrors be limited to 1.4 milliradians. To meet this requirement, the mirror must have a high modulus so that the total weight of the module will not cause a critical deflection in the mirror and thus be out of focus and ineffective. One method of achieving a high modulus without unduly increasing the mass is to design the mirror module as a sandwich structure with skins of relatively high modulus separated by a lightweight core. One of the proposed mirror module designs for the Solar Thermal Large Power System uses a sandwich structure with a $1 / 8$ inch thick glass second surface mirror as the front skin and a 20 gauge galvanized steel sheet as the back skin. Both skins are bonded to a 2-inch thick polystyrene foam core with a polyurethane adhesive. The facing skins in this design act together to resist the externally imposed bending moments and the foam acts to stabilize the skins against buckling and to resist the shear stresses set up by the external loads. The adhesive is used to bond the skins and foam into an integral structure.

High shear loads can be experienced at the bond line and even though an adhesive or cohesive failure may not result, the adhesive may undergo viscoelastic deformation. This deformation may ultimately cause critical deflection of the mirror, at which time it will cease to function effectively. Viscoelastic deformations are defined as time-dependent changes in the material (creep or stress relaxation) under a mechanical load. Creep is the time-dependent change in strain at constant stress, and stress relaxation is the time-dependent change in stress at constant strain. Viscoelastic deformation of the adhesive is, therefore, critical to the functional design of the mirror module. The research studies conducted at PNL and reported in this document were directed toward determining the relationship between viscoelastic deformation of the adhesive and deflection of the mirror module. The results of studies by Hart ${ }^{(1)}$ on long-term compressive creep of polystyrene foam indicate that viscoelastic deformation of the foam core for a mirror module is not significant and was consequently not evaluated in our program. 


\section{THEORETICAL ANALYSIS}

Calculations were made of the forces which might be expected within a foam core sandwich deflected to cause a 1.4 milliradian distortion of a mirror skin. This is the maximum allowable distortion for the mirror, referred to as critical deflection in this report. These calculations were based on a cantilevered foam core sandwich 10 inches long and 2 inches wide with skins of 1/8-inch glass and 20 gauge steel separated by a 2-inch thick polystyrene foam core. Details of the calculations are contained in Appendix $A$. The results are summarized in Table 1, along with the published data on the polystyrene foam proposed for the mirror module. From this analysis, it can be concluded that the foam core has adequate strength to resist an immediate failure when the sandwich is loaded to a point of critical deflection. A calculated force of 9.5 pounds was determined to be necessary to cause a critical deflection. This is equivalent to a compressive loading of approximately 5 psi, a flexure loading of approximately 2 psi, and a shear loading of approximately $1 \mathrm{psi}$. The compressive, flexural, and shear strengths of the foam are $25 \mathrm{psi}, 60 \mathrm{psi}$, and 35 psi, respectively.

TABLE 1. Material Properties of a Polystyrene Core and Theoretical Forces Induced at Critical Deflection

$\begin{array}{ll}\text { Shear strength of Styrofoam IB* } & =35 \mathrm{psi} \\ \text { Shear modulus of Styrofoam IB* } & =1100 \mathrm{psi} \\ \text { Compressive strength of Styrofoam IB* } & =25 \mathrm{psi} \\ \text { Compressive modulus of Styrofoam IB* } & =1000 \mathrm{psi} \\ \text { Flexural strength of Styrofoam IB* } & =60 \mathrm{ps} i \\ \text { Calculated force required for critical } & \\ \text { deflection on a 10-inch span } & \\ \text { (Appendix A) } & =9.5 \text { pounds } \\ \text { Calculated maximum shear stress (at } & \\ \text { steel/foam interface)(Appendix A) } & =0.96 \mathrm{psi}\end{array}$

₹Sytrofoam Brand PTastic Foam, Technical Data, Dow Chemical Corporation. 


\section{VISCOELASTIC ANALYSIS}

Polymers are comprised of a tangle of long-chain molecules which sometimes have crosslinking between the chains. When a stress is applied to a polymer, the molecules tend to relax themselves to release the stress. For instance, a tensile force lower than the ultimate strength of the polymer will cause the molecular chains to straighten out as much as possible. This reorientation takes place slowly and is thus a time-dependent property. Temperature also influences the molecular reorientation since the molecules are able to move more easily at higher temperatures. This action is defined as the viscoelasticity of a polymer and is as important as the static properties of the foam core sandwich in the mirror module. Viscoelastic properties are often evaluated by measuring either stress relaxation (changes in stress under constant strain) or creep (changes in strain under constant stress). These two parameters are mathematically related so either can be measured and related to the other. Stress relaxation is more easily determined experimentally than creep so it is often used for viscoelastic evaluations. One of the inherent problems in this type of testing is the long time periods required to obtain useful data. However, research by Ferry, Williams, Landell and others on polymer systems has resulted in a correlation between time, temperature, and stress which allows superposition of the test data so that long term predictions can be made with short term tests. $(2,3)$ Using this relationship, it is possible to measure viscoelastic parameters for short periods of time at a number of different temperatures and correlate the data to provide a long-time stress relaxation or creep rate for the temperature desired. These extrapolations have proven effective over periods of several hundred hours.

\section{EXPERIMENTAL}

Sandwich test specimens 2 -inches wide by 10-inches long were fabricated by bonding 1/8-inch thick second surface glass mirrors and 20 gauge galvarized steel to the two faces of 1-inch thick Styrofoam 1B (Figure 1). The mirrors were obtained from the Carolina Mirror Company with PPG VC4409 mirror 


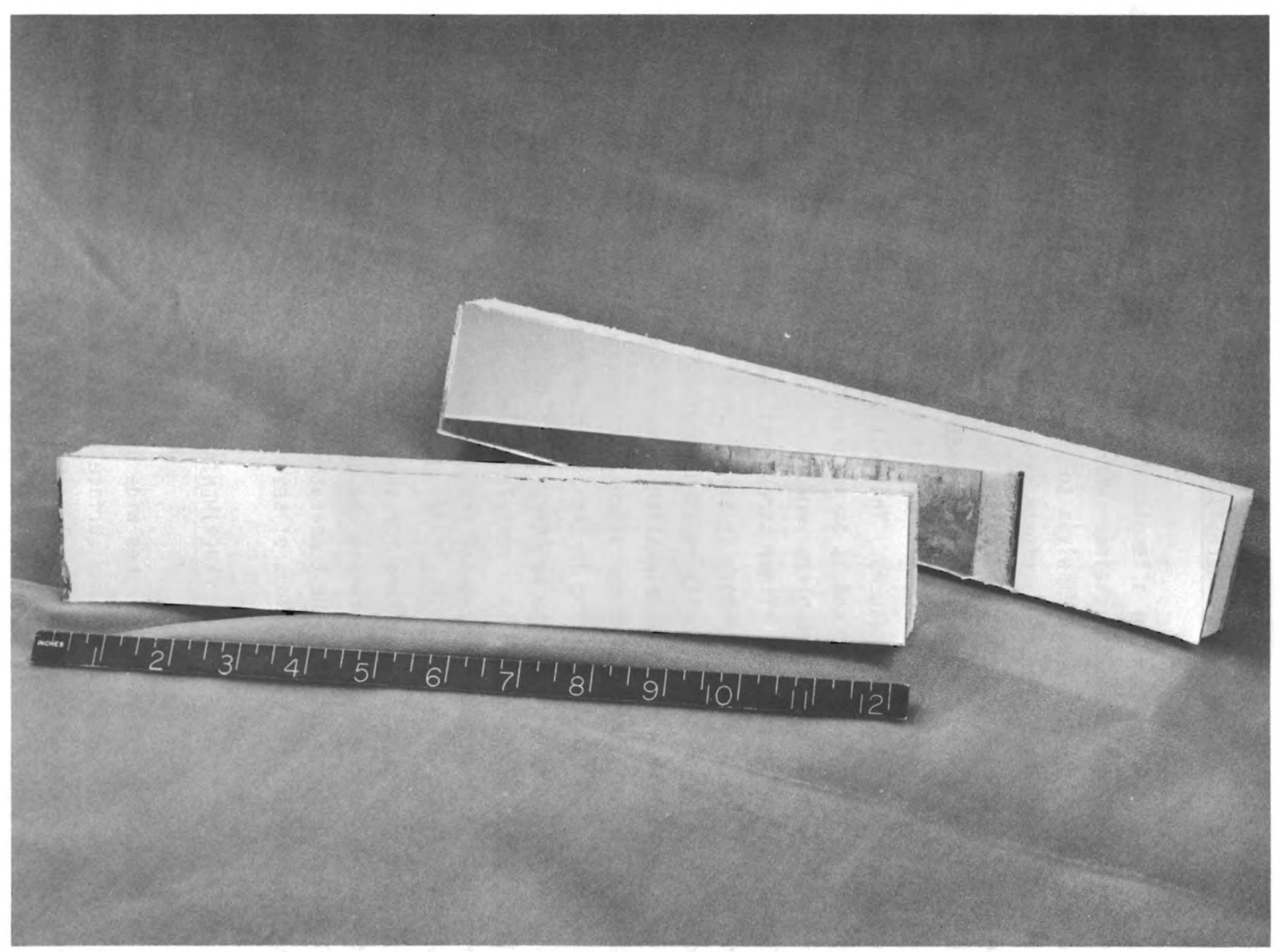

FIGURE 1. Experimental Test Specimens 


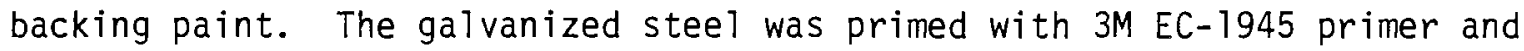
the sandwich was bonded with 3M EC-3549 polyurethane adhesive. The specimens were tested in flexure using three-point bending with an 8-inch span. They were deflected to 0.015 inches and the stress relaxation measurements were made for ten minutes. (Critical deflection for this length of sample is 0.011 inches). The tests were performed at $100^{\circ} \mathrm{F}, 120^{\circ} \mathrm{F}, 140^{\circ} \mathrm{F}$ and $160^{\circ} \mathrm{F}$. They showed no changes in stress at any of the temperatures measured. The failure to show any stress relaxation precludes the use of time-temperature superposition to predict long-term effects. However, the lack of stress relaxation in these tests indicates that the stress levels were too low to cause any viscoelastic reorientation of the polymer molecules. Limited testing was then conducted with 0.050 inches deflection (greater than four times allowable) to see if the additional stress would cause viscoelastic deformation. The results of the latter tests are shown in Figures 2 and 3 . A time-temperature superposition extrapolation of the data was performed. The calculations are included in Appendix $B$ and a graph of the extrapolated data is shown in Figure 4. The curve of Figure 4 is shown as a band rather than a line to include the experimental confidence limits of the data. This curve was then used to calculate the force required to maintain a 0.050 inch deflection of the test sample for 20 years at $100^{\circ} \mathrm{F}$. The modulus value used for the initial conditions was taken from the top of the band and the value at 20 years was taken at the bottom of the band to present the worst case. Under these conditions, the initial force to cause a 0.050 inch deflection is 64 pounds and the force to maintain the deflection after 20 years is 42 pounds. The same calculations were performed with the temperature at $120^{\circ} \mathrm{F}$ and the beginning and 20-year forces were 61 pounds and 33 pounds, respectively. The curve does not allow 20-year extrapolations for temperatures greater than about $130^{\circ} \mathrm{F}$.

The stress relaxation curve used in the above calculations was based on a deflection of 0.050 inches which is significantly greater than the 0.011 inches permitted for a critical deflection. This curve cannot technically be used for determining stress relaxation at critical deflection since the forces calculated would be somewhat lower than they would with the correct 


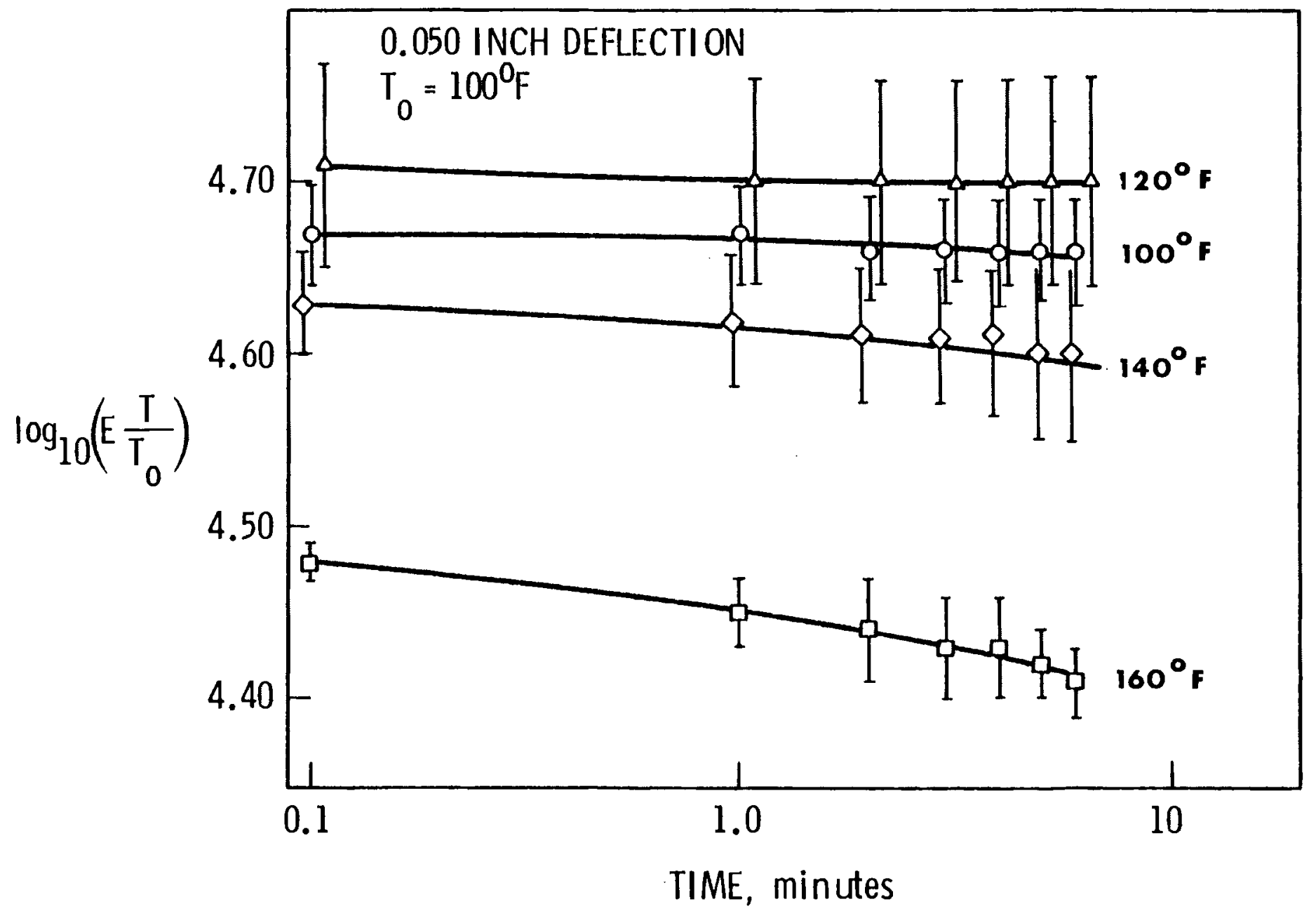

FIGURE 2. Stress Relaxation of Experimental Test Specimens 


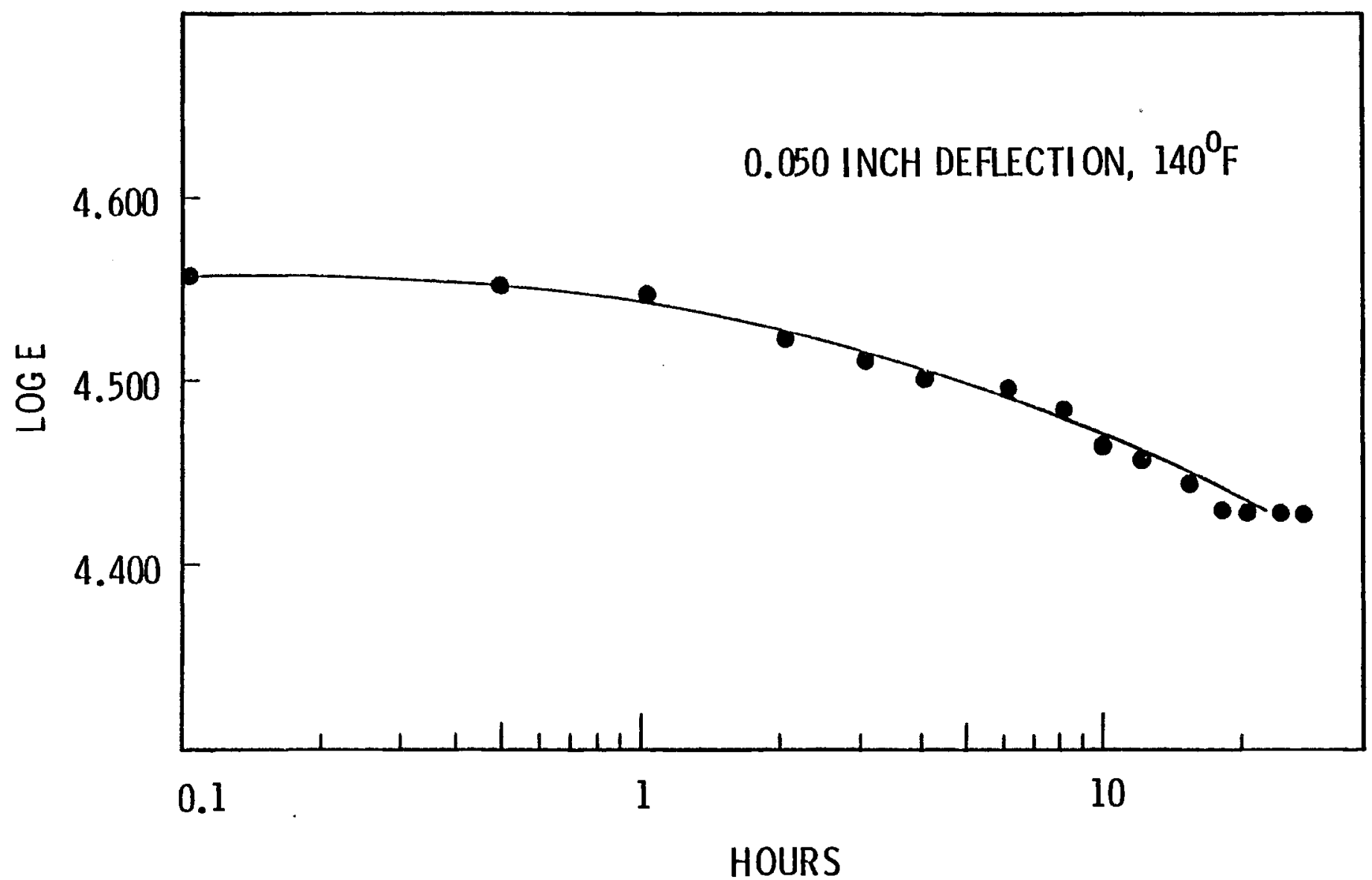

FIGURE 3. 24-Hour Stress Relaxation of an Experimental Test Specimen 


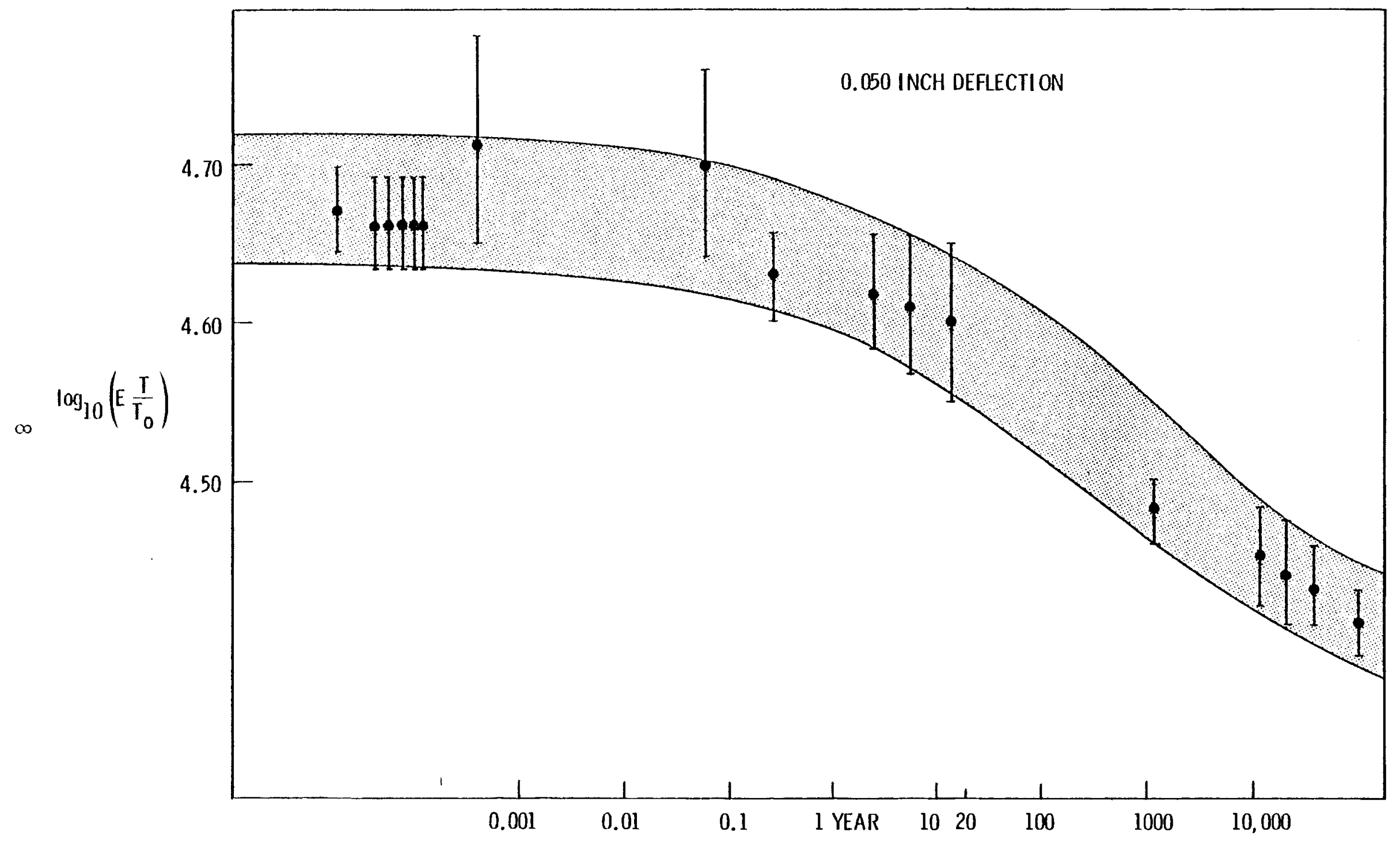

FIGURE 4. Time-Temperature Superposition of Stress Relaxation Test Data 
curve. However, these calculations were performed to give a conservative indication of the general magnitude of the forces involved. At $100^{\circ} \mathrm{F}$ the initial force is 14 pounds and the 20 -year force is 9.3 pounds. At $120^{\circ} \mathrm{F}$ the initial force is 13 pounds and the 20 -year force is 7 pounds. The weight of the mirror sandwich for these test samples with an 8-inch length is 0.36 pounds. Consequently, external forces would be needed to create the necessary conditions for creep deformation of the mirror module.

\section{THERMAL ANALYSIS}

Test specimens fabricated, as described in the previous section, were subjected to thermal cycling (3-hour cycles) to determine if expansion and contraction would cause any visible effects in the sandwich structure. Specimens were cycled 100 times between $160^{\circ} \mathrm{F}$ and $80^{\circ} \mathrm{F}$. There were no visible changes (delamination, warping, etc.) in three samples after this test. Another test was performed to determine what temperatures could be expected at the bond line with the galvanized steel skin of the sandwich facing the sun on a hot day. A panel 12 inches by 12 inches was fabricated by bonding a 20-gauge galvanized stee 1 plate to a 1 -inch thick piece of Styrofoam IB. A thermocouple was embedded at the glue line in the center of the plate. The panel was then placed in the sun in a horizontal plane on the ground with the steel plate up and allowed to come to equilibrium temperature under the following conditions: ambient temperature, $98.6^{\circ} \mathrm{F}$; wind velocity, less than $3 \mathrm{mph}$; insolation on the horizontal, 852 Watts $/ \mathrm{m}^{2}\left(270 \mathrm{BTU} / \mathrm{hr} / \mathrm{ft}^{2}\right)$. The plate reached a maximum temperature of $140^{\circ} \mathrm{F}$. The maximum attainable temperature of a plate will be a function of angle, elevation off the ground, ambient temperature, amount of corrosion of the steel plate, wind velocity and solar insolation. The test conditions were more severe than those that are likely to occur with an actual mirror module. However, if a temperature increase of $40^{\circ} \mathrm{F}$ above ambient is considered possible for a mirror module in operation, it is feasible that the temperature of the steel plate could exceed $160^{\circ} \mathrm{F}$, which is the maximum recommended temperature for the foam core. 


\section{CONCLUS IONS AND RECOMMENDATIONS}

The structural integrity of a polystyrene foam core mirror module appears to be adequate to withstand an external force which would cause the mirror to deflect 1.4 milliradians without an immediate structural failure. It also appears that creep forces greater than 20 times that applied by the weight of the mirror module would be needed to cause the mirror to deflect 1.4 milliradians in 20 years at a continuous temperature of $120^{\circ} \mathrm{F}$. This condition also requires that the mirror remain in the same orientation for that time period. If it is turned up and down every day, the creep forces will tend to cancel out. Because of the conservative nature of the calculations based on stress relaxation with a 0.050 inch deflection and because of the lack of any relaxation with the tests at 0.015 inch deflection, it is our judgment that creep forces will not cause the mirror models to distort beyond its critical limit in 20 years with temperatures up to $150^{\circ} \mathrm{F}$.

Based on these conclusions, the specifications for reflector surface substrates, outlines in Table 2, should be adequate to produce a reliable mirror module for use up to $150^{\circ} \mathrm{F}$. This temperature is approaching the temperature limitations of the poiystyrene foam $\left(160^{\circ} \mathrm{F}\right)$, and if an operating temperature higher than this is expected, further studies to provide data at the expected temperatures should be conducted.

TABLE 2. Specifications for Reflector Surface Substrates

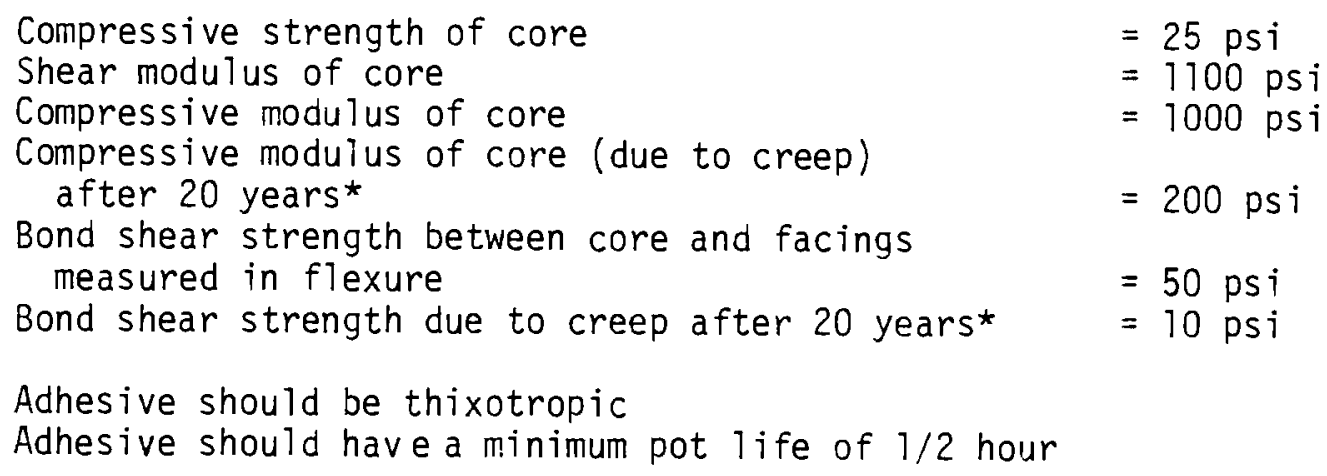

Adhesive should be thixotropic

Adhesive should have a minimum pot 1 ife of $1 / 2$ hour

\footnotetext{
*Long-time performance as predicted by accepted superposition principles.
} 


\section{APPENDIX A}

The following equations used for theoretical analysis of a structural sandwich are found in Gibbs \& Cox: (4)

$$
\begin{gathered}
d=\frac{P L^{3}}{3 E I}\left[1+\frac{h^{2} e}{4 L^{2}}\right] \\
2 e=\frac{E_{x f}}{G_{f}}\left[2-3\left(\frac{c}{h}\right)+\left(\frac{c}{h}\right)^{3}\right]+\frac{E_{x c}}{G_{c}}\left[3 r\left(\frac{c}{h}\right)-3 r\left(\frac{c}{h}\right)^{3}+2\left(\frac{c}{h}\right)^{3}\right] \\
r=\frac{E_{x f}}{E_{x c}} \\
f_{x}=\frac{V Q}{E I b}
\end{gathered}
$$

$P=V=10 a d$

$d=$ deflection

$E=$ flexural modulus of elasticity

$I=$ moment of inertia

$G=$ shear modulus

$Q=$ weighted static moment $=\Sigma E_{i} A_{i} y^{\prime}$

$f_{S}=$ shear stress

$A=$ shear area

$y^{\prime}=$ distance from neutral axis to any point being evaluated

Other symbols and their values are as indicated in Figure $A-1$.

Equivalent areas and widths of the sandwich are calculated using the equations

$$
A_{2}^{\prime}=A_{2} \times \frac{E_{1}}{E_{2}} \text { and } b^{\prime}=\frac{A^{\prime}}{t}
$$

*Equation numbers from the reference are used for utility.

$$
\text { A }-1
$$




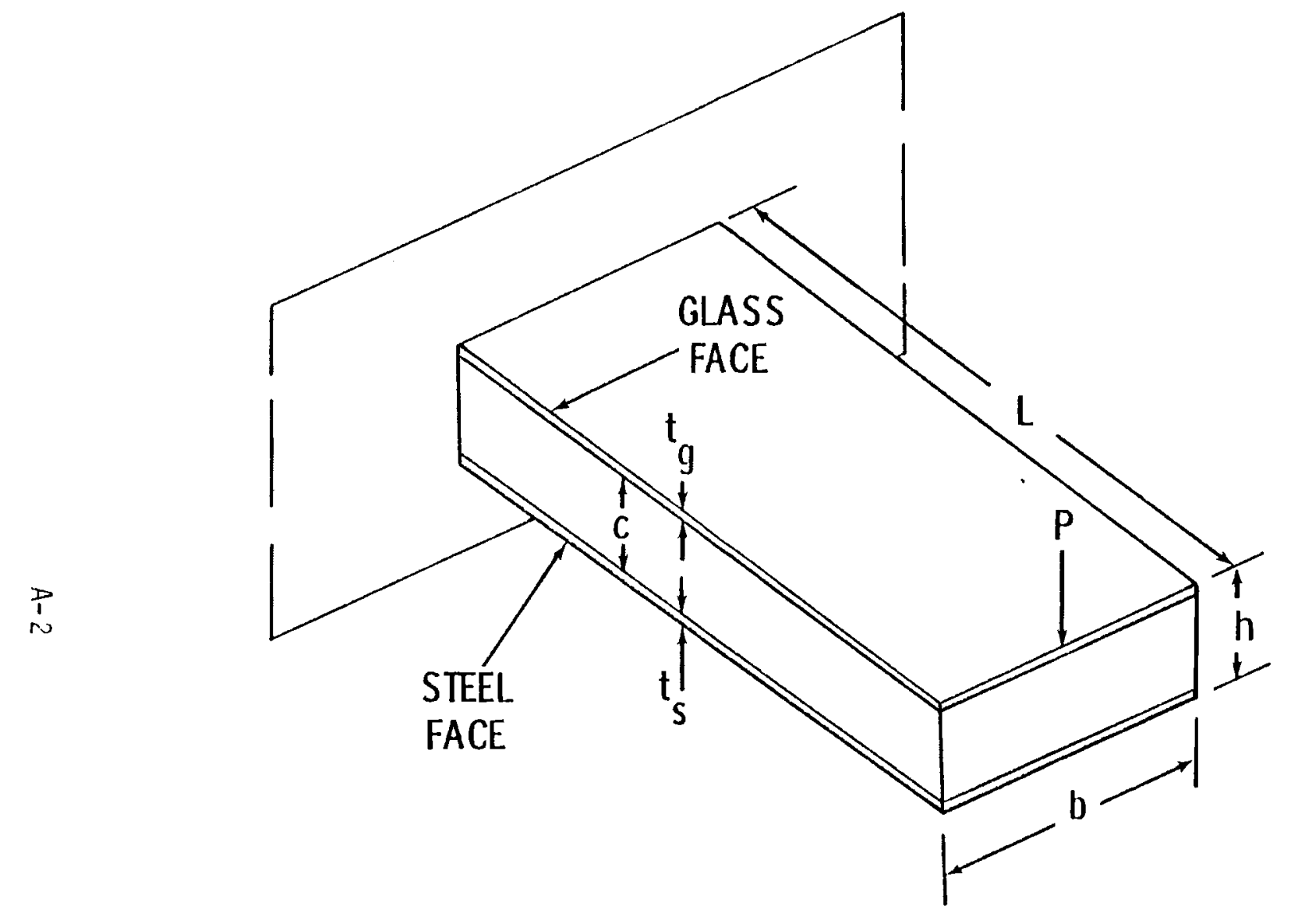

FIGURE A-1. Sandwich Structure Used For Theoretical Analysis

$$
\begin{aligned}
E_{f g} & =9.5 \times 10^{6} \\
G_{f g} & =3.96 \times 10^{6} \\
E_{f s} & =30 \times 10^{6} \\
G_{f s} & =13 \times 10^{6} \\
E_{c} & =2000 \\
G_{c} & =1100 \\
b & =2 \text { inches } \\
c & =2 \text { inches } \\
t_{g} & =0.125 \text { inches } \\
t_{s} & =0.025 \text { inches } \\
L & =10 \text { inches }
\end{aligned}
$$


The area of the glass is used as a basis

$$
\begin{gathered}
A_{g}{ }^{\prime}=A_{g}=0.125 \times 2=0.250 \mathrm{in}^{2} \quad b_{g}{ }^{\prime}=2^{\prime \prime} \\
A_{C}{ }^{\prime}=2 \times 2 \times \frac{2000}{9.5 \times 10^{6}}=8.4 \times 10^{-4} \mathrm{in}^{2} \quad b_{c^{\prime}}{ }^{\prime}=4.2 \times 10^{-4} \\
A_{S^{\prime}}{ }^{\prime}=0.025 \times 2 \times \frac{30 \times 10^{6}}{9.5 \times 10^{6}}=0.16 \mathrm{in}^{2} \quad b_{s^{\prime}}=6.4^{\prime \prime}
\end{gathered}
$$

neutral axis of the sandwich $=x=\frac{\sum A^{\prime} \chi^{\prime}}{\sum A^{\prime}}$

taking moments around the bottom of the steel face

$$
\begin{aligned}
& x=\frac{(0.16)(0.0125)+8.4 \times 10^{-4} \times 1.025+0.25 \times 2.088}{0.16+8.4 \times 10^{-4}+0.25} \\
& x=1.277
\end{aligned}
$$

equivalent moment of inertia

$$
I^{\prime}=\Sigma\left[\frac{b_{j}^{\prime} t_{i}^{3}}{12}+A_{i}^{\prime} x_{i}^{2}\right]
$$

and the equivalent stiffness factor

$$
\begin{gathered}
E I^{\prime}=\Sigma E_{i} I_{i}=\Sigma E_{i}\left[\frac{b_{i}^{\prime} t_{i}^{3}}{12}+A_{i}^{\prime} x_{i}^{2}\right] \\
E I=9.5 \times 10^{6}\left[\frac{2 \times 0.125^{3}}{12}+0.250 \times 0.811^{2}\right]+2000\left[\frac{4.2 \times 10^{-4} \times 2^{3}}{12}+\right. \\
\left.8.4 \times 10^{-4} \times 0.252^{2}\right]+30 \times 10^{6}\left[\frac{6.4 \times 0.025^{3}}{12}+0.16^{1} \times 1.252^{2}\right] \\
=1.565 \times 10^{6}+0.667+7.52 \times 10^{6}=9.089 \times 10^{6}
\end{gathered}
$$


$2 e$ is calculated using Equation 6.87 for two glass faces and two steel faces then averaged to obtain e for the sandwich.

For two glass faces

$$
\begin{aligned}
& 2 \mathrm{e}=\frac{9.5 \times 10^{6}}{3.96 \times 10^{6}}\left[2-3\left(\frac{2}{2.15}\right)+\left(\frac{2}{2.15}\right)^{3}\right]+\frac{2000}{1100}\left[3 \times \frac{9.5 \times 10^{6}}{2000}\left(\frac{2}{2.15}\right)-\right. \\
& \left.\quad 3 \times \frac{9.5 \times 10^{6}}{2000}\left(\frac{2}{2.15}\right)^{3}+2\left(\frac{2}{2.15}\right)^{3}\right] \\
& 2 \mathrm{e}=3249
\end{aligned}
$$

For two steel faces

$$
\begin{aligned}
& 2 \mathrm{e}=\frac{30 \times 10^{6}}{13 \times 10^{6}}\left[2-3\left(\frac{2}{2.15}\right)+\left(\frac{2}{2.15}\right)^{3}\right]+\left[\frac{2000}{1100} 3 \times \frac{30 \times 10^{6}}{2000}\left(\frac{2}{2.15}\right)-\right. \\
& \left.\quad 3 \times \frac{30 \times 10^{6}}{2000}\left(\frac{2}{2.15}\right)^{3}+2\left(\frac{2}{2.15}\right)^{3}\right] \\
& 2 e=10,252
\end{aligned}
$$

$$
2 e \text { avg }=\frac{10,252+3249}{2}=6751
$$

maximum allowable deflection $=1.4 \times 10^{-3} \mathrm{~L}$ inches

from Equation 6.86

$$
\begin{aligned}
& P=\frac{d 3 E I}{L^{3}\left[1+\frac{h^{2} e}{4 L^{2}}\right]} \\
& P=9.5 \text { lbs force to cause maximum deflection }
\end{aligned}
$$


shear is calculated from equation 6.37. For shear at the glass/foam bond line

$$
\begin{gathered}
y^{\prime}=0.748 \text { inches } \\
f s=\frac{9.5 \times 9.5 \times 10^{6} \times 2 \times 0.125 \times 0.748}{9.089 \times 10^{6} \times 2}=0.93 \mathrm{psi}
\end{gathered}
$$

For shear at the steel/foam bond line

$$
\begin{gathered}
y^{\prime}=1.227 \text { inches } \\
f s=\frac{9.5 \times 30 \times 10^{6} \times 2 \times 0.025 \times 1.227}{9.089 \times 10^{6} \times 2}=0.96 \text { psi }
\end{gathered}
$$




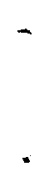




\section{APPENDIX B}

Williams, Landel and Ferry ${ }^{(3)}$ have developed equation $B-1$ (the WLF equation) which defines a single function $\left(A_{T}\right)$ that can be used to represent the time/temperature dependence of viscoelastic properties:

$$
\log A_{T}=C_{1}^{0}\left(T-T_{0}\right) /\left(C_{2}^{0}+T-T_{0}\right)
$$

In using this equation $\Delta \log A_{T}$ is determined by physically measuring the distance between the stress relaxation curves for different temperatures. These measurements are then summed to obtain $\log A_{T}$ at the experimental temperatures. $T-T_{0} / \log A_{T}$ is then plotted as a function of $T-T_{0}$ and $c_{1}^{0}=-\frac{1}{\text { stope }}$ and $C_{2}^{0^{0}}=\frac{y \text { intercept }}{\text { slope }}$. This process was followed to develop the values of Table B-1. Since the relaxation data wasn't sufficient to produce overlapping curves, the $140^{\circ} \mathrm{F}$ curve was extrapolated and pseudo curves for $120^{\circ} \mathrm{F}$ and $150^{\circ} \mathrm{F}$ were added as shown by the dashed lines in Figure $B-1$. The plot of $T-T_{0} / \log A_{T}$ vs $T-T_{0}$ is shown in Figure $B-2$. The calculated $\log A_{T}$ column in Table $B-1$ is determined by using the constants $C_{1}^{0}$ and $C_{2}^{0}$ obtained from Figure $B-2$ and plugging them into Equation $B-1$. The calculated $A_{T}$ values are used as the shift factors to produce Figure 4.

\section{TABLE B-1}

\begin{tabular}{|c|c|c|c|c|c|}
\hline $\mathrm{T},{ }^{\circ} \mathrm{K}$ & $\Delta T$ & $\triangle \log A_{T}$ & $\underline{\log A_{T}}$ & $\begin{array}{c}\Delta \mathrm{T} \\
\log A_{T}\end{array}$ & $\operatorname{calc} \log A_{T}$ \\
\hline \multicolumn{6}{|l|}{311} \\
\hline 322 & 11 & 6 & 6 & 1.833 & 5.6 \\
\hline 333 & 22 & 5 & 11 & 2.00 & 12.7 \\
\hline 338.5 & 27.5 & 5.8 & 16.8 & 1.637 & \\
\hline 344 & 33 & 5.7 & 22.5 & 1.467 & 21.9 \\
\hline
\end{tabular}

The calculations to determine the forces required for critical deflection at time and temperature are as follows: 


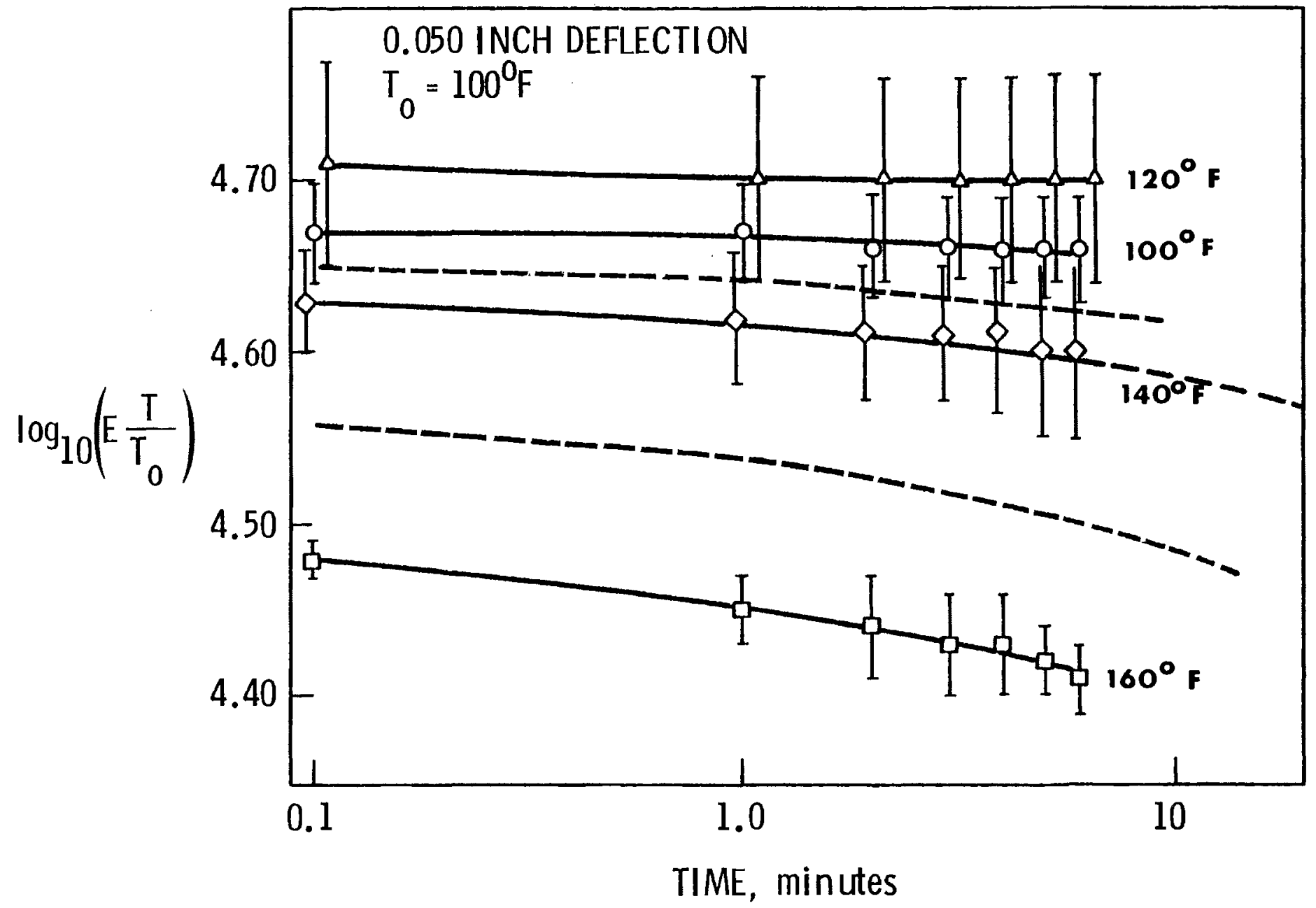

FIGURE B-1. Stress Relaxation Curves Used For Time-Temperature Superposition 
$\stackrel{\infty}{\omega}$

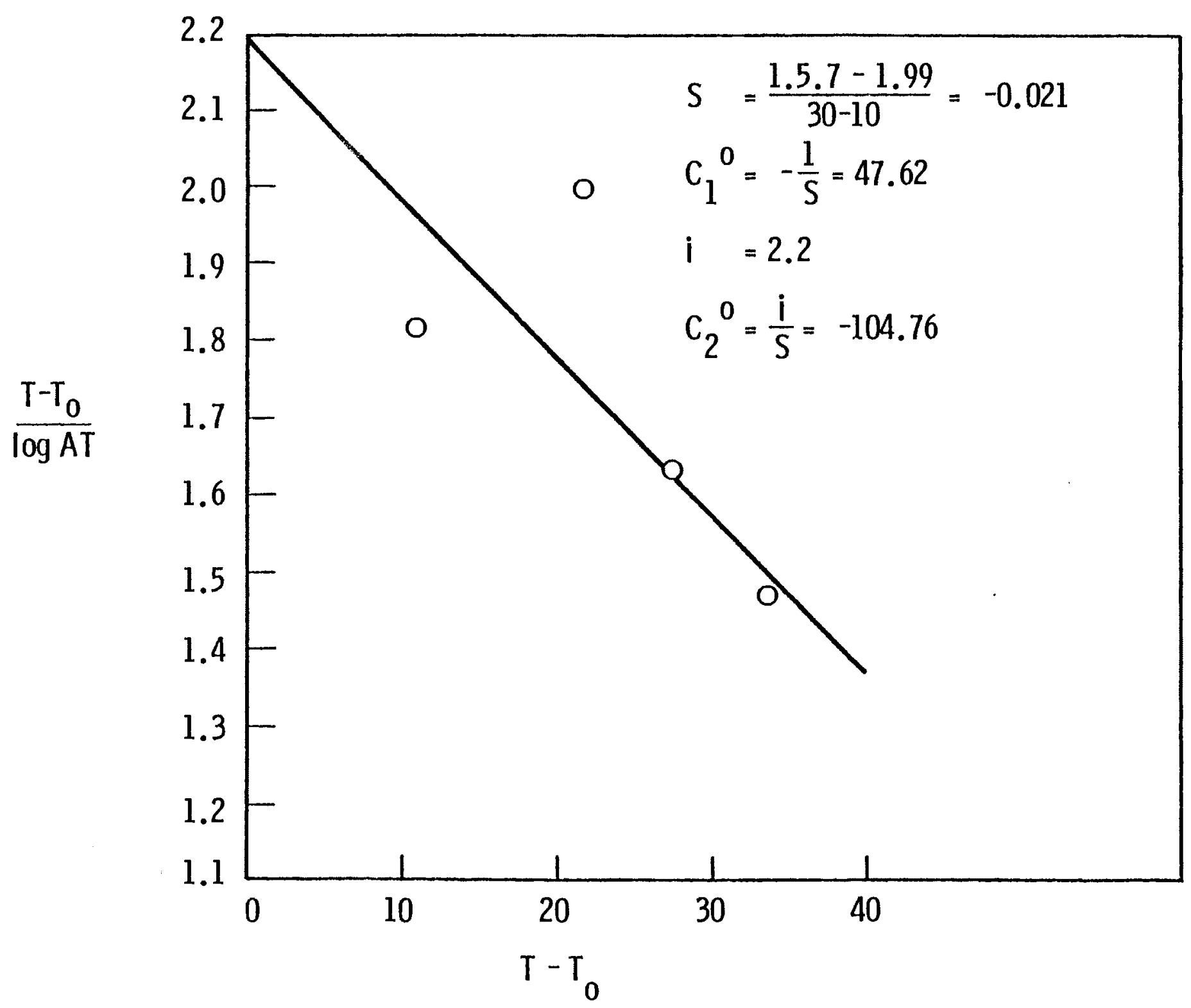

FI. RE B-2. Determination of the WLF Constants 
Worst case at $100^{\circ} \mathrm{F}$

$\log E \frac{T}{T_{0}}=4.72$ at time 0 and 4.54 after 20 years

$E=5.248 \times 10^{4}$ psi at start

$E=3.467 \times 10^{4}$ psi after 20 years

$$
E=\frac{L^{3} \times P}{4 \times b \times d^{3} \times \text { deflection }}
$$

$L=$ span length $=8$ inches

$P=$ force

$b=$ width $=2$ inches

$d=$ thickness $=1.160$ inches

for a deflection of 0.050 inches

$$
P=\frac{E}{820}
$$

$P_{\text {start }}=64$ pounds

$P_{20}=42$ pounds

for a deflection of 0.011 inches

$$
P=\frac{E}{3727}
$$

$P_{\text {start }}=14$ pounds

$P_{20}=9.3$ pounds

Worst case at $120^{\circ} \mathrm{F}$

$\log E \frac{T}{T_{0}}=4.72$ at start and 4.45 after 20 years

$E=5.012$ psi at start

$E=2.692$ psi after 20 years 
for a deflection of 0.050 inches

$$
P=\frac{E}{820}
$$

$P_{\text {start }}=61$ pounds

$P_{20}=33$ pounds

for a deflection of 0.011 inches

$$
P=\frac{E}{3727}
$$

$P_{\text {start }}=13$ pounds

$P_{20}=7$ pounds 



\section{REFERENCES}

1. G. M. Hart, C. F. Balazs and R. B. Clipper, "Prediction of the Long-Term Compressive Creep Behavior of Cellular Polystyrene," Journal of Cellular Plastics, Vol. 9, No. 3, May/June 1973.

2. John D. Ferry, Viscoelastic Properties of Polymers, John Wiley \& Sons, 1961.

3. Eric Baer, Engineering Design for Plastics, Reinhold Publishing Corp. 1964.

4. Gibbs \& Cox, Inc., Marine Design Manual for Fiberglass Reinforced Plastics, Mc-Graw Hil1 Book Co., 1960. 



\section{DISTRIBUTION}

No. of

Copies

OFFSITE

1 DOE Chicago Patent Group 9800 South Cass Avenue Argonne, IL 60439

A. A. Churm

6 DOE-Division of Solar Technology 20 Massachusetts Avenue Washington, DC 20545

G. Braun

M. U. Gutstein

G. M. Kaplan

L. Melamed

J. E. Rannels

J. Weissinger

27 DO5 Technical information Center

1 Ed Beauchamp

Sandia Laboratories

Org. 5846

Box 5800

Albuquerque, NM 87115

1 Pat Call

SERI

1536 Cole BIvd.

Golden, CO 80401

1 William Carroll

Jet Propulsion Laboratory 4800 Oak Grove Drive

Pasadena, CA 91103

1 Roscoe L. Champion

Sandia Laboratories

Division 5711

Albuquerque, NM 87115
No. of

Copies

OFFSITE

1 William R. Delemeter

Sandia Laboratories

Division 8122

Livermore, CA 94550

1 John J. Dietrich

McDonne11 Douglas

5301 Bolsa

Huntington Beach, CA 92660

1 Robert A. England

Martin Marietta

MS S0403

P 0 Box 179

Denver, C0 80201

$1 \quad J i m$ Leonard

Sandia Laboratories

Box 5800

Albuquerque, NM 87115

1 I. Earl Lewis

Ford Aerospace \& Communications

Corporation

3939 Fabian Way

Palo Alto, CA 94303

1 Matt McCargo

Lockheed PaTo Aito Research Labs

B1dg. 205 Dept. 5232

3251 Hannover Street

Palo Alto, CA 94304

10

Clayton L. Mavis

Sandia Laboratories

Division 8131

Livermore, CA 94550 


\section{DISTRIBUTION}

No. of

Copies

OFFSITE

1 William D. Mitchell

Solaramics

1301 El Segundo Blvd.

El Segundo, CA 90245

1 Timothy K. Muller ACUREX

485 Clyde Avenue

Mountain View, CA 94042

1 Richard Pettit

Sandia Laboratories

Division 5842

A1buquerque, NM 87115

1 Charles J. Pignolet

Sandia Laboratories

P 0 Box 969

Livermore, CA 94550

1 David Rostoker

Pittsburgh Corning Corporation 800 Presque Isle Dr.

Pittsburgh, PA 15239

1 Arthur Slemnons

SRI-Internationa 1

333 Ravenswood Avenue

Men 1o Park, CA 94025

1 W. Tomlinson

Environmental Library University of Montana

758 Eddy Street

Missoula, MT 59812

1 John G. Vega

Martin Marietta

P O Box 179, MS 8120

Denver C0 80201
No. of

Copies

OFFSITE

1 LeRoy Weinstein

McDonnel1 Douglas

5301 Bolsa Avenue

Huntington Beach, CA 92660

1 Solomon Zwerdling

Northeast Solar Energy Center

70 Memorial Drive

Cambridge, MA 02142

1 Andy Kraynik

Sandia Laboratories

Division 5813

Kirkland AFB

ATbuquerque, NM 87185

\section{ONSITE}

2 DOE Richland Operations Office H. E. Ransom

Bob Stewart

43 Pacific Northwest Laboratory

T. D. Chikalla

W. J. Coleman

K. Drumbeller

N. R. Gordon (25)

A. J. Haverfield

M. A. Lind (5)

R. P. Marshal1

G. L. Tingey

Publishing Coordinator (2)

Technical Information Files 